sions of the sexual instinct are most happily handled by suggestion. Melancholia and paranoia in general form a fruitful field for its application.

Suggestion may be administered in the waking state, but the happiest manner of presenting it is in the hypnotic state, because in that state there exists the special form of passivity which is most conducive to the highest receptivity of suggestion. After a patient has been hypnotized several times this method is dispensed with and euggestions made in the waking state. By reason of the fact that the subjective mind is incapable of inductive reasoning, it is necessary that the successive steps to be pursued in the treatment of any given case should be specifcaliy outlined at the beginning of each sitting in order that the best results may be attained. This rule is equally applicable to suggestive treatment in the waking state, as such methods are based on pure psychologic grounds and tend to secure the greatest degree of confidence in the line of treatment adopted and best operates to secure the establishment of ideo-motor and ideo-dynamic impulses in the restoration of healthy function.

The phenomena of perverted functional activity have long been before $\mathrm{us}$, the fullest application of the cure is yet to be made, for as yet we have only vaught a glimpse of the boundless possibilities of suggestive therapeutics coupled with a judicious use of specific drugs. Bernheim says: "It is a physiologic law, that sleep puts the brain into such psychic condition that the imagination does accept and recognize as real the impressions transmitted to it. To provoke this special psychic condition by means of hypnotism and cultivate the suggestibility thus artificially increased with the aim of cure or relief, is the rôle of the psycho-therapeutics." Couple with this a careful scientific explanation of the functions of the disordered part and the specific line of action of any drug in aidıng nature in the cure of the condition, and an ideal line of treatment is established. While suggestive therapeutics is not a new subject, it has only within the past few years been placed upon anything like a scientific basis. With the advance in our knowledge regarding the physiology of function through physiologic chemistry and psychology we are becoming better prepared to direct it. The power of the imagination has long been called upon to assist in the cure of diseased conditions. Lack of knowledge as to how the special functions of the body produce results has prevented the intelligent use of this agent in the past. History is, however, full of the miraculous cures of all manner of disorders. The strong hold that faith cure and Christian science have gotten upon the people, witnesses the power of suggestion in the treatment of disease.

Suggestive therapeutics, like all other lines of treatment, has its limitations, else final dissolution could be abolished. The first limit is lack of faith in the complete efficacy of the remedy. We stop short of success in many things in life by reason of our inability to persist to a finish. This is not always the result of lack of faith, but is, many times, a physical defect. Poor human nature becomes exhausted, and we give up the ghost, literally as well as figuratively. There is a limit to the resistive quality of protoplasm just as positively as there is a pcint where cohesion in the molecules of the irregular
metals fails, and yet it goes without dispute that depressions. the will has saved the life of many a man by carrying him over the crisis. Physicians all recognize it in the treatment of disease.

In conclusion, I desire to say that I am a firm be. liever in the value of suggestion in medical practice. and that experience, based upon years of scientific study in the phenomena of function, leads me to earnestly advocate the use of hypnotic suggestion alone in the treatment certain forms of disease and its general use as an adjunct to already accepted therapeutic measures.

100 state Street.

\section{A SIMPLE METHOD OF DRESSING FRAC- TURES OF THE EXTREMITIES. AN AUXILIARY TO THE BANDAGE.}

Read in the Section on surgery and Anatomy, at the Forty-sixtb Annual Meeting of the American Medical Association, at Baltimore. Md., May 7-10, 1895.

BY JOHN EPH. LINK, M.D.

TERRE HAUTE, IND.

My object in this paper with demonstration, is to present a simple, effective and convenient method of dressing injuries of the extremities, especially the lower, whether of fracture as the paper is headed or dislocations, sprains or contusions and lacerations of muscle or tendon, everything indicating rest of tissue; a dressing embracing the principle of rest without restraint; a simple auxiliary to the bandage.

I hope to be able to demonstrate at some future time that all progressive tendency to displacement from reflex irritation can be avoided by placing the muscles in a state of rest by simply encasing the limb in an easy enviroument.

The bandage of old, well worn muslin in successive layers comes as near meeting these indications as any other and with nack can be made almost, if not quite, as effective in soft even cushioning as with the cotton batting and much more retaining.

The device that I have adopted is the thin shavings of birch wood used in commerce for packing tubs and buckets, which I here present; and as you will, I think, readily comprehend enables one to lay the bandage equally as smoothly and is a safe-guard, against their being easily displaced; a most desirable consideration where it is so desirable, as in cases of fracture, to maintain the parts in a fixed position for a considerable length of time. The advantage of this over the plaster dressing is two-fold, first, ventilation, the admitting of free air and free exhalation from the body, as we have markedly here the advantage in irrigation aud washing of limb and dressings without removing the covering. The bandage and splints are susceptible of being washed clean from all fouling of secretions; even the skin made so in bathing through the covering either with hot or cold water, as may be preferred, in a few minutes time, by continuous irrigation. After a thirty minutes' washing the dressing will again dry in a little longer time, say in one hour. The special advantage that I have found in the use of the shavings of wood over zinc tin, is that there is just sufficient roughness in their surfaces to make a firm cohesion with the bandage when applied wet, and more or less pliable alike whether wet or dry, and in their extreme thinness, easily fitted, by fraying, to the irregularities of the limb, protuberances and depressions. 
You will notice in the illustration I present you that the spreading is easy and graceful, fitting over the enlargements and that the overlapping at points of narrowing is not bungling; and further with a pair of blunt scissors which you may carry in your vest pockets, the parts of segments can be clipped away so as to avoid even this small amount or irregular thickening if desired, and at the same time not interfere with the utility of the splint, and as layer after layer can be sandwiched with the consecutive layers of the bandage we can easily so shift the pieces as to compensate in the one for the deficit of the other, and when after the limb is once so environed we have lightness and strength combined, a perfect retention with a minimum part of cumberous restraint to the injured tissue. There will be also a lack of the feeling of arbitrary force as in the more cumbersome dressing and, as I think you will at once comprehend, a better physiologic reparative condition.

Excuse me, if I here may seem to impose upon your time and patience in suggesting a further thought,

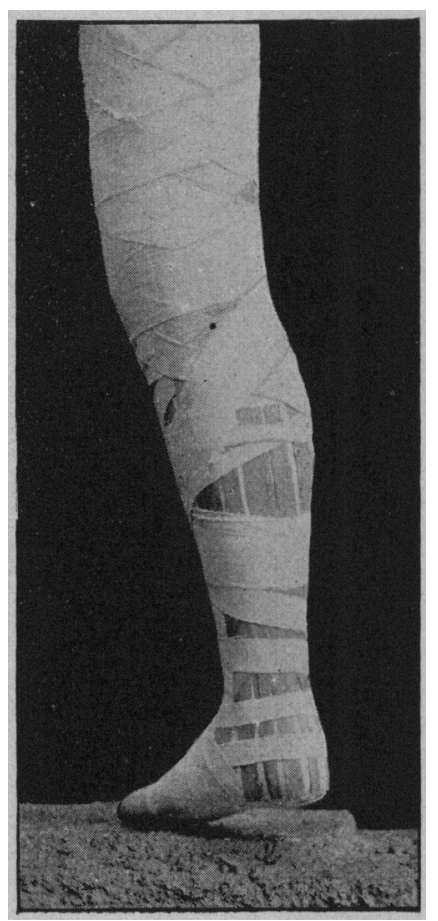

As applied on an artificial limb for demonstration before the session.

that with the interwoven splint and lines of the roller bandage circular, diagonal and longitudinal, up and down the axis of the limb, that the changing of any part of your dressing to the extent of weakening the support or adding to the discomfort of the patient by fulling in cords drawing or pressing from thickening, as is liable to be the case in the cotton under the plaster, or of the plain roller bandage, without stiffening. You will find after weeks of wearing of the shavings that your dressing, bandage and everything else is as smooth and perfect as the hour you first adjusted it.

My experience in observation is that there will be, in no instance, that stiffness of joint or shrinkage in the muscles as is apt to be the case with the more stiff and arbitrary enveloping of the limb, as in plaster or silicate dressings. There will be, at no time, during the time of applying this dressing any danger of losing the proper control of the injured member, as from sudden stiffening nor delay of hardening, as in the use of plaster of paris.

The nature of the stiffening from non-friableness and cohesiveness of the wood and muslin as above, is such that if timely looked to can be changed a little here or there, more or less. You will, I have no doubt, be surprised to learn, in some of these efforts at changing, and appreciate the firmness with which even a small piece or mere splinter, it may be, will remain in its place and thus be assured of the reliability of the method. When you have finished with a few layers completely surrounding the limb, you can lift it with impunity, changing from place to place with the least danger of displacement of the fragment and a minimum of discomfort to your patient. I can only assure you that I have frequently dressed a compound fracture of the leg with loss of substance of tibia and fibula of several inches, with perfect results in the normal line and length. The parts were kept healthy and clean by irrigation or washing for weeks, and until repair was perfect, without changing.

\section{ASEPSIS AND ANTISEPSIS IN OTOLOGY.}

BY J. HOLINGER, M.D.

chICAgo.

The application of the principles of asepsis in all their details has brought great progress in general surgery, in bygiene and in the particular branches of gynecology, obstetrics and ophthalmology; but in some other departments of medicine much is still to be done, before the ideal condition desired by the friends of asepsis will have been attained. Among these latter it seems to me that otology must be included, and that as regards it, the greatest number of scientists underrate the value and misunderstand the necessity for the strictest asepsis. Of course in large operations the instruments are boiled, the patient is cleaned, and as a rule the operator's hands are more or less carefully disinfected. But between this and a complete, consistent and thorough asepsis there is a wide difference. The principles of asepsis should be carried out in otology in the routine examinations of the ear, and especially in the seemingly unimportant details of ambulatory practice. A little reflection will show that hardly anywhere is strict asepsis of more value than in ambulatory practice. Except in cases of very small children we have to use instruments in every examination, and to use them in parts of the body normally covered by only a very tender epidermis, parts that are not accustomed to nor able to endure irritations and that hence are extremely vulnerable. Furthermore, there is no physician who comes so much into contact with putrid and virulently infective material as the otologist. Yet it must be admitted that there are many otologists who do not acknowledge the necessity of asepsis in their department. Their view is not based upon the ab. sence of ill results in their cases, because such results do exist though they are not always readily recognizable and their recognition demands an experienced eye. Even when recognized, there is often lacking in those who are responsible for them the courage to admit them either in public or in private. If a confinement case be managed improperly and uncleanly, the evidences of infection will appear within a few days at the very spot where it occurred 